\title{
REVIEW
}

\section{FGF23 signalling and physiology}

\author{
Bryan B Ho and Clemens Bergwitz \\ Department of Internal Medicine, Section Endocrinology, Yale University School of Medicine, New Haven, Connecticut, USA
}

Correspondence should be addressed to C Bergwitz: clemens.bergwitz@yale.edu

\begin{abstract}
Fibroblast growth factor 23 (FGF23) is a phosphotropic hormone that belongs to a subfamily of endocrine FGFs with evolutionarily conserved functions in worms and fruit flies. FAM20C phosphorylates FGF23 post-translationally, targeting it to proteolysis through subtilisin-like proprotein convertase FURIN, resulting in secretion of FGF23 fragments. O-glycosylation of FGF23 through GALNT3 appears to prevent proteolysis, resulting in secretion of biologically active intact FGF23. In the circulation, FGF23 may undergo further processing by plasminogen activators. Crystal structures show that the ectodomain of the cognate FGF23 receptor FGFR1c binds with the ectodomain of the co-receptor alpha-KLOTHO. The KLOTHO-FGFR1c double heterodimer creates a high-affinity binding site for the FGF23 C-terminus. The topology of FGF23 deviates from that of paracrine FGFs, resulting in poor affinity for heparan sulphate, which may explain why FGF23 diffuses freely in the bone matrix to enter the bloodstream following its secretion by cells of osteoblastic lineage. Intact FGF23 signalling by this canonical pathway activates FRS2/RAS/RAF/MEK/ERK1/2. It reduces serum phosphate by inhibiting 1,25-dihydroxyvitamin D synthesis, suppressing intestinal phosphate absorption, and by downregulating the transporters NPT2a and NPT2c, suppressing phosphate reabsorption in the proximal tubules. The physiological role of FGF23 fragments, which may be inhibitory, remains unclear. Pharmacological and genetic activation of canonical FGF23 signalling causes hypophosphatemic disorders, while its inhibition results in hyperphosphatemic disorders. Non-canonical FGF23 signalling through binding and activation of FGFR3/FGFR4/calcineurin/NFAT in an alpha-KLOTHO-independent fashion mainly occurs at extremely elevated circulating FGF23 levels and may contribute to mortality due to cardiovascular disease and left ventricular hypertrophy in chronic kidney disease.
\end{abstract}

Key Words
- FGF23
- FGF receptor
- KLOTHO
PTH
- phosphate homeostasis
- phosphate signalling
- mineralisation
- erythropoetin
- iron
- hematopoesis
- CKD

\section{Introduction}

Fibroblast growth factor 23 (FGF23) is a phosphotropic hormone that belongs, along with FGF19 and 21, to a subfamily of endocrine FGFs (Château et al. 2010). FGF23 is secreted by osteoblasts and osteocytes into the systemic circulation and acts in the kidney, parathyroid, heart, bone and possibly other organs (Shimada et al. 2004, Krajisnik et al. 2007, Faul et al. 2011, Murali et al. 2016b).
This property sets FGF23 apart from paracrine FGFs, which mediate cell and organ differentiation locally. FGF23 also stands apart from the intracrine FGFs, which act intracellularly independently of an FGF receptor (FGFR) by interacting with voltage-gated sodium channels and neuronal scaffolding proteins to potentiate neuronal excitability (Goldfarb et al. 2007, Itoh et al. 2016). 
FGF23 was first discovered in the murine brain (Yamashita et al. 2000) and soon thereafter loss-of-function (LOF) mutations were identified by linkage analysis to be the cause of autosomal dominant hereditary rickets (ADHR) (ADHR-Consortium 2000) and tumour-induced osteomalacia (TIO) (Shimada et al. 2001). ADHR and TIO are rare renal phosphate wasting disorders characterised by, through different mechanisms, hypophosphatemic rickets and osteomalacia, which leads to bowing of the long bones, short stature, bone pain, muscle weakness and fractures (Carpenter et al. 2020).

FGF23 hassincebeen shown to be a critical phosphaturic hormone which, along with parathyroid hormone (PTH), regulates phosphate recycling and synthesis of calcitriol $\left(1,25\right.$-Dihydroxyvitamin D or $\left.1,25(\mathrm{OH})_{2} \mathrm{D}\right)$ in the kidneys (Shimada et al. 2004). Canonical FGF23 signalling requires the obligatory co-receptor alpha KLOTHO (KL), a transmembrane protein with extracellular glucuronidase activity (Tohyama et al. 2004), for binding to the FGF receptor 1c (FGFR1c) (Urakawa et al. 2006). Still, some FGF23 signalling occurs independently of KL and is often referred to as non-canonical FGF23 signalling.

Here we review the current understanding of the actions of FGF23 and the signalling pathways involved. FGF23, in turn, is regulated by phosphate, inflammation and energy metabolism, which we will not discuss here because it has been addressed in several recent reviews (Faul 2012, Clinkenbeard \& White 2017, Chande \& Bergwitz 2018, Michigami et al. 2018, Takashi \& Fukumoto 2020).

\section{Evolutionary conservation of KL/FGF23 function}

Orthologs of the FGF signalling pathway are found in Caenorhabditis elegans and Drosophila melanogaster (Château et al. 2010). Even KL and FGF23 functions are evolutionary conserved. C. elegans has two FGF orthologs, egg-laying-defective 17 (Egl-17) (Burdine et al. 1997) and lethal-756 (Let-756) (Roubin et al. 1999); one FGFR ortholog, Egl-15 (DeVore et al. 1995); and two KL orthologs, Klo-1 and Klo-2 (Table 1) (Château et al. 2010). Egl-15 activity is negatively regulated by N-glycosylation, which inhibits ligand and heparan sulphate binding to this receptor (Polanska et al. 2009), in a similar manner to human FGFR activity (Duchesne et al. 2006). Egl-15 has also been shown to associate with Klo-1 by co-immunoprecipitation using monoclonal Klotho or Egl-15 antibodies (Polanska et al. 2011), though further work is necessary to determine, if Egl-15 binds to Klo-1 in a fashion similar to KL and FGFR, and if Klo-1 and Klo-2 are necessary for Egl-15 activity. Activation of

Table 1 FGF, FGFR, and KL Orthologs in Caenorhabditis elegans and Drosophila melanogaster.

\begin{tabular}{|c|c|c|}
\hline Species & Ortholog & General function \\
\hline \multirow[t]{2}{*}{ C. elegans } & $\begin{array}{l}\text { FGF: Egl-17 } \\
\text { Let-756 (Szewczyk and } \\
\text { Jacobson 2003) }\end{array}$ & $\begin{array}{l}\text { Egl-17: Longevity, oxidative } \\
\text { stress resistance } \\
\text { Let-756: Fluid homeostasis }\end{array}$ \\
\hline & $\begin{array}{l}\text { FGFR: Egl-15 (Szewczyk and } \\
\text { Jacobson 2003) } \\
\text { KL: Klo-1 } \\
\text { Klo-2 (Château et al. 2010) }\end{array}$ & $\begin{array}{l}\text { Receptor for Egl-17 and } \\
\text { Let-756 } \\
\text { Improve longevity and } \\
\text { resistance to oxidative } \\
\text { stress }\end{array}$ \\
\hline \multirow[t]{3}{*}{ D. melanogaster } & $\begin{array}{l}\text { FGF: bnl, pyr, ths } \\
\text { (Rose et al. 2019) }\end{array}$ & bnl: promote Pi excretion \\
\hline & $\begin{array}{l}\text { FGFR: btl, htl } \\
\text { (Rose et al. 2019) }\end{array}$ & $\begin{array}{l}\text { btl: bnl receptor } \\
\text { htl: pyr and ths receptor }\end{array}$ \\
\hline & $\begin{array}{l}\text { KL: CG7901 } \\
\text { (Rose et al. 2019) }\end{array}$ & Unknown \\
\hline
\end{tabular}

\begin{tabular}{l} 
Gain/loss of function consequences \\
\hline LOF Egl-17: defective migration and \\
differentiation of sex myoblasts \\
LOF Let-756: larval developmental arrest \\
LOF both Egl-17 and Let-756: suppression of \\
muscle lysis \\
GOF: Muscle lysis, abnormal fluid filling in \\
pseudocoelom \\
Unknown \\
LOF during development: absent trachea \\
resulting in death \\
Injection of human FGF23 in adults: increased \\
MFS2 expression, decreases blood Pi \\
LOF during development: absent trachea \\
resulting in death \\
LOF in adults: blocks hypophosphatemic \\
response to injection of human FGF23 \\
Unknown
\end{tabular}

Orthologs to human FGF, FGFR, and KL in C. elegans and D. melanogaster, including their general function and consequences of alterations of activity, are listed as mentioned in the text.

bnl, branchless; btl, breathless; Egl-15/17, egg-laying-defective 15/17; FGF, fibroblast growth factor; FGFR, fibroblast growth factor receptor; GOF, gain-offunction mutation; htl, heartless; KL, Klotho; Klo, Klotho-ortholog; Let-756, lethal-756; LOF, loss-of-function mutation; MFS2, major facilitator superfamily 2; pyr, pyramus; ths, thisbe. 
Egl-15 by Egl-17 or Let-756 results in muscle lysis (Szewczyk \& Jacobson 2003). Loss-of-function mutation in Egl-17 leads to defective migration and differentiation of sex myoblasts (Burdine et al. 1997), and loss-of-function mutation in Let-756 leads to larval developmental arrest (Roubin et al. 1999). These effects resemble the roles of FGFs in morphogenesis in higher species and suggest these orthologs may share properties similar to those of multiple FGFs in higher species. Interestingly, like ablation of FGF23 and KL in higher species, LOF mutations in Klo-1 and Klo-2 also reduced stress tolerance and longevity in C. elegans (Polanska et al. 2009, Château et al. 2010). Conversely, the gain of function in Egl-15 leads to fluid accumulation in the animal's pseudocoelom, hinting at the roles of FGF23 and KL in mineral excretion in higher species (Huang \& Stern 2004).

Likewise, D. melanogaster has three FGF orthologs, branchless (bnl), pyramus (pyr), and thisbe (ths); two FGFR orthologs, breathless (btl) and heartless (htl); and one KL ortholog (CG9701) which were identified through the DRSC integrative ortholog prediction tool (DIOPT) (Table 1) (Rose et al. 2019). As in humans, these FGFR orthologs signal via the MAPK pathway (Sen et al. 2011). We recently showed that flies microinjected with human FGF23 become hypophosphatemic. This hypophosphatemia appears to be due to upregulation of the type I sodiumdependent Pi co-transporter major facilitator superfamily 2 (MFS2) in their Malpighian tubules (Rose et al. 2019). Ablation of MFS2 prevents this FGF23 effect and also blocks the formation of fly calcium Pi kidney stones.
Based on expression in the tubule and stimulation of MFS2 gene expression by dietary Pi and FGF23, MFS2 may function as an excretory Pi-transporter in the Malpighian tubules. This function is different from the situation in mammalian kidneys, where the type II sodium-dependent Pi co-transporters NPT2a and NPT2c help reclaim Pi from the urine and may reflect the unique anatomy of the fly renal system, which lacks a connection to a glomerulus as seen in higher species (Rose et al. 2019), and absence of skeletal mineral stores for Pi. The roles of the FGF, FGFR, and KL orthologs in D. melanogaster in Pi homeostasis require further study, although in particular bnl may promote Pi excretion as transgenic overexpression of bnl increases MFS2 expression (Rose et al. 2019).

\section{Structure and biochemistry}

FGF23 is a 251-amino acid, $32 \mathrm{kDa}$ protein, with high N-terminal homology to other FGFs (Yamashita et al. 2000). Phosphorylation of FGF23 through the extracellular kinase family member 20C (FAM20C) at amino acid S180 prevents post-translational O-glycosylation by polypeptide $\mathrm{N}$-acetylgalactosaminyltransferase 3 (GALNT3) (Fig. 1). Lack of O-glycosylation makes FGF23 susceptible to proteolysis by the subtilisin-like proprotein convertase FURIN. Proteolysis of FGF23 results in the secretion of inactive FGF23 fragments (Tagliabracci et al. 2014). FGF23 phosphorylation can be detected in bone sections and FAM20C-transfected cells (Lindberg et al. 2015) underlining its biological importance. Conversely,

Unprocessed FGF23 Transcript

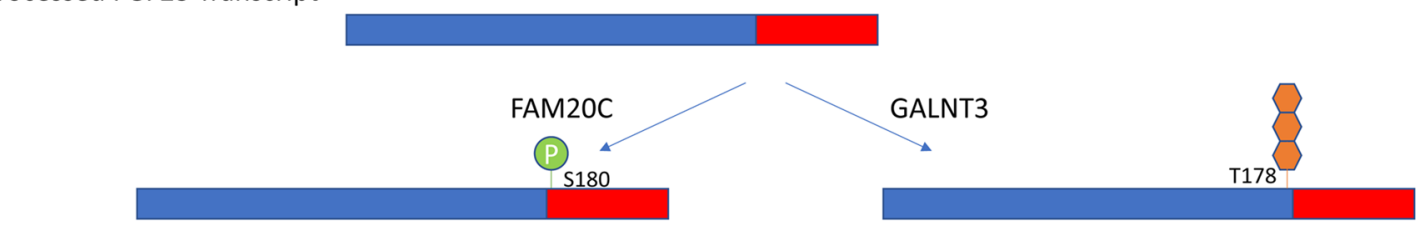

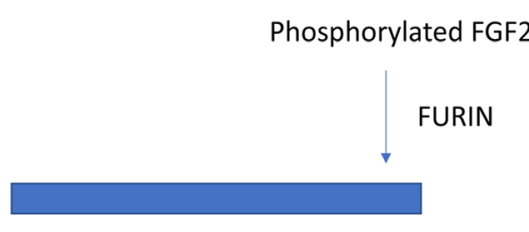

Inactive $\mathrm{N}$-terminal fragment

Blocking C-terminal fragment

O-glycosylated active FGF23

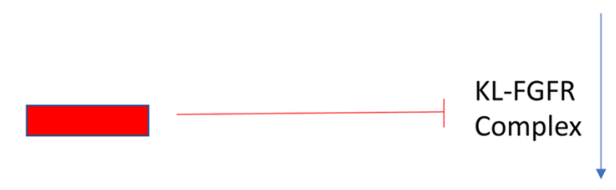

\section{Figure 1}

Post-translational modification of FGF23. FGF23 is a 251 -amino acid $32 \mathrm{kDa}$ protein. Phosphorylation by FAM20C at amino acid S180 is cleaved by FURIN into biologically inactive FGF23 fragments. Unprocessed transcripts can also be O-glycosylated by GALNT3 into biologically active FGF23. Cleavage by FURIN is suppressed by O-glycosylation of FGF23 and may be regulated by the elusive endocrine Pi sensor. The C-terminal fragment may serve as the endogenous inhibitor of KL-FGFR complex formation. FGF23, fibroblast growth factor 23; FAM20C, extracellular kinase family member 20C; FURIN, subtilisin-like proprotein convertase; GALNT3, N-acetylgalactosaminyltransferase 3; KL-FGFR, Klotho-fibroblast growth factor receptor complex. 
phosphorylation and proteolysis by FURIN are prevented by O-glycosylation at position T178 through GALNT3, which results in the secretion of the biologically active intact FGF23 (Tagliabracci et al. 2014). The regulation of transcription, production, and post-translational modification of FGF23 has been recently reviewed in greater detail (Edmonston \& Wolf 2020).

Regulation of FGF23 bioactivity by GALNT3 and FAM20C is still poorly understood but may be controlled by the elusive endocrine Pi-sensor (Takashi \& Fukumoto 2020). Impaired processing and inactivation of FGF23 play an essential pathophysiological role in the development of FGF23 excess in chronic kidney disease (CKD). Excess circulating FGF23 causes left ventricular hypertrophy (LVH) in CKD patients (Faul et al. 2011) and the autosomal dominant version of hypophosphatemic rickets (ADHR) as recently reviewed (Wolf \& White 2014).

Furthermore, C-terminal fragments of FGF23 may serve a physiological role as an endogenous inhibitor to the formation of the KL-FGFR complex (Goetz et al. 2010) and to full-length FGF23 signalling, which may subsequently induce hypophosphaturia (Goetz et al. 2010) and raise serum iron levels (Agoro et al. 2020), but this and the signalling pathways involved remain poorly understood.

Likewise, whether biologically meaningful cleavage and inactivation of intact FGF23 in the circulation occurs is poorly understood. FGF23 cleavage and inactivation may involve the actions of both tissue-type and urokinase plasminogen activators. Genetic ablation of Pai-1, an inhibitor of plasminogen activator, for example, can rescue the phenotype of the $\mathrm{Kl}$-null mouse (Eren et al. 2017). As a result, these authors speculated that inhibition of PAI-1 could be used pharmacologically to prevent FGF23 excess and the development of LVH in patients with CKD.

\section{FGF23 signalling}

FGFs signal through the four FGF tyrosine kinase receptors (FGFR1-4) and thereby activate the RAS-MAPK and the PI3K-AKT pathways (Ornitz \& Itoh 2015). While FGF23 can activate FGFR3 and FGFR4 in a KL-independent fashion (Grabner et al. 2015, Murali et al. 2016b),

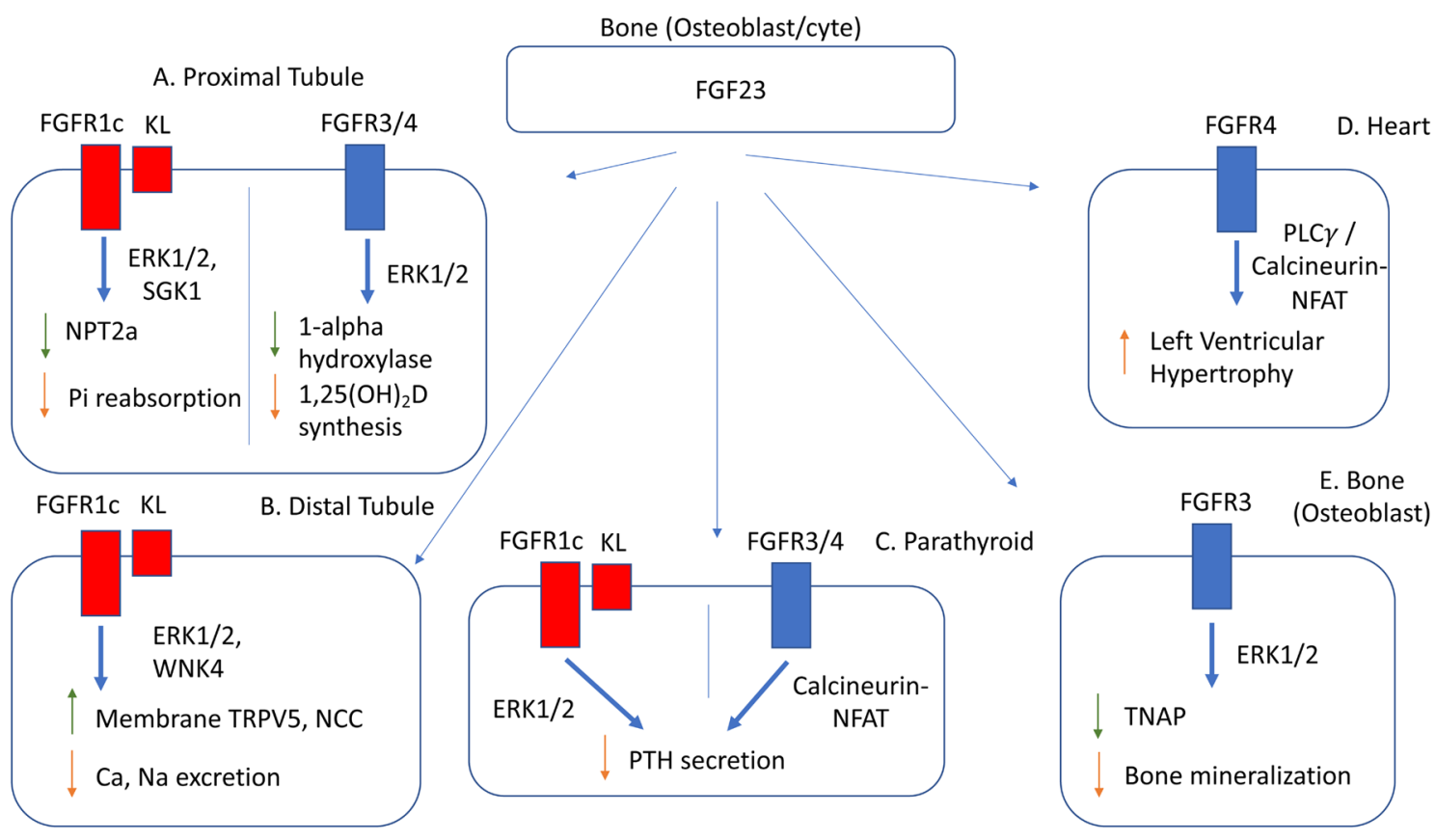

Figure 2

Canonical and non-Canonical FGF23 Signaling. FGF23 is a peptide hormone secreted by bone that affects multiple organ systems. (A) In the proximal tubules, FGF23 caused internalisation of sodium type 2 co-transporter NPT2a in a FGFR1c/KL-mediated manner by activation of ERK1/2 and SGK1 (red, canonical). FGF23 also decreased activation of vitamin D in a KL-independent fashion (blue, non-canonical). (B) In the distal tubules, FGF23 causes $\mathrm{KL}$-dependent stimulation of calcium and sodium reabsorption. (C) In the parathyroid glands, FGF23 causes suppression of PTH secretion, likely through KL-dependent and -independent pathways. (D) In the heart, FGF23 causes LVH in a KL-independent manner in a FGFR4 mediated fashion mediated by PLCgamma/NFAT/calcineurin. (E) In osteoblasts, FGF23 inhibits bone mineralisation by decreased expression of the phosphatase TNAP in a KL-independent fashion. FGF23, fibroblast growth factor 23; FGFR, fibroblast growth factor receptor; NPT2a, sodium-phosphate cotransporter 2a; ERK1/2, extracellular signal-regulated kinases 1/2; SGK1, serum/glucocorticoid regulated kinase 1; WNK4, serine/threonine-protein kinase WNK4; NFAT, nuclear factor of activated T-cells; PLCgamma, phosphoinositide phospholipase C gamma; TNAP, tissue nonspecific alkaline phosphatases; TRPV5, transient receptor potential vanilloid 5 (calcium channel protein); NCC, sodium chloride cotransporter. 
Table 2 Serum and urine biochemistries of mouse models of disorders in phosphate homeostasis.

\begin{tabular}{|c|c|c|c|c|c|c|c|}
\hline \multirow[b]{2}{*}{ Model } & \multicolumn{5}{|c|}{ Serum } & \multicolumn{2}{|c|}{ Urine } \\
\hline & Calcium & Phosphate & $\underline{\text { FGF23 }}$ & PTH & $1,25(\mathrm{OH})_{2} \mathrm{D}$ & Calcium & Phosphate \\
\hline KI-I- (Yoshida et al. 2002, Segawa et al. 2007) & $\uparrow$ & $\uparrow$ & $\uparrow \uparrow$ & $\downarrow$ & $\uparrow$ & $\uparrow$ & - \\
\hline Kap- KI-I- (Ide et al. 2016) & - & - & - & - & - & - & - \\
\hline Pepck-KI-I- (Ide et al. 2016) & - & - & $\uparrow \uparrow$ & - & - & - & $\downarrow$ \\
\hline Slc34a1-KI-/- (Ide et al. 2016) & $\uparrow$ & $\uparrow$ & - & - & - & - & $\downarrow \downarrow$ \\
\hline Ksp-KI-/- (Olauson et al. 2012) & - & $\uparrow$ & $\uparrow$ & $\downarrow$ & - & $\uparrow$ & - \\
\hline Fgf23-1- (Shimada et al. 2004, Hesse et al. 2007) & $\uparrow$ & $\uparrow$ & $\downarrow \downarrow$ & $\downarrow$ & $\uparrow$ & - & - \\
\hline Hyp (Eicher et al. 1976, Murali et al. 2016a) & $\downarrow$ & $\downarrow$ & $\uparrow$ & - & - & N.d. & $\uparrow$ \\
\hline Fgfr1-/- (Gattineni et al. 2009) & N.d. & - & $\uparrow$ & - & - & N.d. & N.d. \\
\hline Fgfr3-/- (Gattineni et al. 2009) & N.d. & - & - & - & $\uparrow$ & N.d. & N.d. \\
\hline Fgfr4-/- (Gattineni et al. 2009) & N.d. & - & $\uparrow$ & - & $-/ \uparrow$ & N.d. & N.d. \\
\hline Ksp-Fgfr1-/- (Han et al. 2016) & - & $\downarrow$ & - & $\uparrow$ & - & $\uparrow$ & $\uparrow$ \\
\hline gGt-Fgfr1-/- (Han et al. 2016) & - & $\uparrow$ & - & - & - & - & - \\
\hline Ndrg1-CreERT2; Fgfr1-4-/- (Takeshita et al. 2018) & - & $\uparrow$ & $\uparrow$ & $\downarrow$ & $\uparrow$ & N.d. & N.d. \\
\hline
\end{tabular}

Overview of the mouse models that have contributed to our understanding of phosphate homeostasis. Each strain is compared to its appropriate WT control.1,25- $(\mathrm{OH})_{2} \mathrm{D}$, calcitriol, 1,25-dihydroxyvitamin D; FGF23, fibroblast growth factor 23; Fgfr-1-, fibroblast growth factor receptor-null mouse model; gGt-Fgfr1-1-, Fgfr1-ablation in the proximal tubule by gamma-glutamyltransferase (gGt)-Cre-recombinase; Hyp, Phosphate-regulating gene with homologies to endopeptidases on the X chromosome (PHEX)-deficient mouse model of X-linked hypophosphatemia (XLH); Kap-KI-/-, KI-ablation in the proximal tubules mediated by Kidney androgen-regulated protein (Kap)-Cre-recombinase; Kl-/-, Klotho-null mouse model; Ksp-Fgfr1-/-, Fgfr1-ablation in the distal tubule by Kidney-specific cadherin (Ksp)-Cre-recombinase; Ksp-Kl-l-, Kl-ablation in the distal tubules mediated by kidney-specific cadherin (Ksp)-Cre-recombinase; N.d., no data; Ndrg1-CreERT2;Fgfr1-4-1-, Tamoxifen-induced Fgfr1-4-ablation in the proximal tubule by N-myc downstream-regulated gene-1 (Ndrg1)-Crerecombinase; Pepck-KI-l-, Kl-ablation in the proximal tubules mediated by Phosphoenolpyruvate carboxykinase (Pepck)-Cre-recombinase; PTH, parathyroid hormone; S/c34a1-Kl-1-, Kl-ablation in the proximal tubules mediated by Solute carrier family 34 member 1 (SIc34a1)-Cre-recombinase.

FGFR1c appears to be the primary endocrine receptor for FGF23 which requires the presence of KL (Kurosu et al. 2006). Recent crystal structure data suggest that this receptor isoform, together with $\mathrm{KL}$, but independent of its beta-glucuronidase enzymatic activity, forms a binding pocket for the C-terminal region of c-FGF23 (Chen et al. 2018). Heparan sulphate, which unlike other paracrine FGFs has a weak affinity to FGF23 itself, facilitates the dimerisation of two 1:1:1 FGF23-FGFR1c-KL complexes into a symmetric 2:2:2:2 FGF23-FGFR1cKL-HS signal transduction unit (Chen et al. 2018). The osteocyte extracellular matrix is a heparan sulphate-rich environment, which limits systemic diffusion of paracrine FGFs, and these authors hypothesise that reduced affinity to heparan sulphate therefore promotes systemic circulation of FGF23 (Beenken \& Mohammadi 2012).

Commonly, FGF23 signalling through KL-dependent binding to FGFR1c is referred to as 'canonical'. Conversely, FGF23 signalling through KL-independent binding to FGFR3 and FGFR4 is referred to as 'non-canonical'. Figure 2 for details of canonical and non-canonical signalling and Table 2 for the various animal models that helped shape the current understanding of FGF23 signalling and physiology.

\section{Canonical FGF23 signalling}

The phosphaturic effects of FGF23 in the kidney tubules are KL-dependent. In the proximal renal tubules, membrane levels of the sodium-phosphate co-transporters, NPT2a and NPT2c, are reduced by FGF23. The internalisation and degradation of these phosphate transporters increases phosphate excretion and was shown to depend on the activation of the extracellular signalregulated kinases 1/2 (ERK1/2) and serum/glucocorticoidregulated kinase-1 (SGK1) pathways (Andrukhova et al. 2012), resulting in phosphorylation of the $\mathrm{Na}+\mathrm{H}+$ exchange regulatory factor (NHERF1) (Fig. 2A) (Deliot et al. 2005). An initial question was the site of action of FGF23 in the kidneys since KL is expressed highly in the distal renal tubules (Kuro-O et al. 1997). KL was furthermore shown to co-localise with phosphorylated-ERK1/2 in the distal tubules following FGF23 injection of mice (Farrow et al. 2009). This was corroborated by co-localisation of high $\mathrm{KL}$ expression with the calcium channel protein transient receptor potential vanilloid 5 (TRPV5) in the distal tubules (Chang et al. 2005). Furthermore, targeted deletion of $\mathrm{KL}$ in the distal tubule with Ksp-Cre elevated serum $\mathrm{Pi}$, which is consistent with resistance to FGF23 in the distal tubules, while interestingly $1,25(\mathrm{OH})_{2} \mathrm{D}$ remained normal (Table 2) (Olauson et al. 2012).

However, low levels of KL expression in the proximal tubule was ultimately demonstrated along with FGFR1, 3, and 4 expression (Andrukhova et al. 2012). Multiple groups have now shown that FGF23 stimulates both fibroblast growth factor receptor substrate 2 (FRS2) and ERK1/2 in the proximal tubule (Urakawa et al. 2006, Andrukhova 
et al. 2012). Targeted ablation of KL using three proximal tubule-specific promoters driving Cre, Kap, Pepck, and SLC34a1 (Table 2), increased serum Pi and reduced urine $\mathrm{Pi}$, suggesting that FGF23 regulates re-absorption of $\mathrm{Pi}$ in a KL-dependent manner in the proximal tubules (Ide et al. 2016). Likewise, conditional ablation of Fgfr 1 in the distal tubule (Ksp-Cre) caused hypophosphatemia and hypercalciuria whereas ablation in the proximal tubule (gGt-Cre) resulted in hyperphosphatemia (Fig. 2B). At the same time, $1,25(\mathrm{OH})_{2} \mathrm{D}$ levels were unchanged (Han et al. 2016). Tamoxifen-induced conditional ablation of Fgfr1-4 in the proximal tubule (Ndrg1-CreERT2) likewise caused hyperphosphatemia, although along with an increase in $1,25(\mathrm{OH})_{2} \mathrm{D}$ levels, which will be discussed further (Takeshita et al. 2018).

Conversely, global ablation of Fgfr 3 and 4 decreased $1,25(\mathrm{OH})_{2} \mathrm{D}$ levels in mice (Table 2) (Gattineni et al. 2009). These results suggest that $1,25(\mathrm{OH})_{2} \mathrm{D}$ and 1-alphahydroxylase regulation may be mediated through FGFR3 and FGFR4 in a KL-independent manner, which would formally be considered non-canonical (see below). However, KL-deficient mice have highly increased serum $1,25(\mathrm{OH})_{2} \mathrm{D}$ and 1-alpha-hydroxylase levels, which resemble findings in FGF23-deficient mice. This notion argues that FGF23 suppresses 1-alpha-hydroxylase at least in part in a KL-dependent fashion (Shimada et al. 2004).

FGF23 affects calcium homeostasis in the distal tubules, which express the calcium channel protein transient receptor potential vanilloid 5 (TRPV5) in the apical membrane, a transporter that reabsorbs calcium from the urine (Hoenderop et al. 1999). KL deglycosylates and thereby retains TRPV5 in the apical distal tubule membrane (Chang et al. 2005). This process appears to be stimulated by FGF23: recombinant FGF23 injections increased membrane TRPV5 expression and decreased urinary calcium excretion in WT but not Klotho-deficient mice, which appears to be mediated by FGFR, ERK1/2 and serum/glucocorticoid-regulated kinase-1 (SGK1) (Andrukhova et al. 2012). Furthermore, KL-deficient and FGF23-deficient mice showed profound hypercalciuria. FGF23 stimulates formation of TRPV5- serine/threonineprotein kinase 4 (WNK4) complexes (Fig. 2B).

Sodium is reabsorbed in the distal tubules by a thiazidesensitive sodium-chloride cotransporter (NCC) (Gamba et al. 1993). This transporter appears to be regulated by FGF23 in a KL-dependent fashion. Expression of NCC and thus sodium reabsorption is decreased in an FGF23deficient mouse model, and conversely injection of FGF23 into WT mice results in increased sodium reabsorption and volume expansion, an effect not observed with inhibition of ERK1/2 or SGK1 or following the injection of FGF23 into KL-null mice (Andrukhova et al. 2014). FGF23 has also been shown to reduce expression of angiotensinconverting enzyme 2 (ACE2), a component of the reninangiotensin system, and thus has been proposed to participate systemically in blood pressure regulation and to prevent angiotensin-related cardiac remodeling as recently reviewed (Kovesdy \& Quarles 2016). The contribution of FGF23 excess to volume expansion seen in CKD may warrant further study.

Parathyroids in $\mathrm{Kl}$-null mice have a reduced setpoint for calcium (Mace et al. 2018) which may be due to decreased expression of $\mathrm{Na} / \mathrm{K}$-ATPase and is independent of FGF23 (Imura et al. 2007). In addition, FGF23 reduces PTH secretion in the parathyroid gland, which may have KL-dependent and -independent mechanisms (Fig. 2C). A murine chronic kidney disease (CKD) model exhibited decreased $\mathrm{Kl}$ and Fgfr1 expression (Ben-Dov et al. 2007). Presence of secondary hyperparathyroidism in these mice was interpreted by the authors as indirect evidence for Klotho-dependence of PTH suppression by FGF23. However, FGF23 was able to suppress PTH in a parathyroid-specific Kl-null mouse model (Olauson et al. 2013). Suppression of PTH secretion by FGF23 was abolished by addition of the calcineurin-NFAT pathway inhibitor cyclosporine A, arguing that this action of FGF23 is, at least partially, KL-independent (Olauson et al. 2013) Furthermore, broad FGFR inhibition by PD173074 in Wistar rats (Mace et al. 2018) and inhibition of ERK1/2 by U0126 (Ben-Dov et al. 2007) or by recombinant dualspecific phosphatases (Dusp) (Román-García et al. 2012) in ex vivo parathyroid cultures prevented suppression of PTH secretion in response to recombinant FGF23.

There is some evidence that canonical FGF23 signalling may finally play a role in the pathophysiology of tumour-induced osteomalacia (TIO). TIO is caused by mesenchymal tumours often described as hemangioperitomas, which secrete FGF23 and cause a paraneoplastic renal phosphate wasting syndrome with osteomalacia and muscle weakness (Carpenter et al. 2020). RNA-seq analysis of FGF23-producing tumours revealed fibronectin (FN)-FGF1 or FN-FGFR1 gene rearrangements, which may activate FGFR1 in an autocrine fashion that stimulates FGF23 production by these tumours (Lee et al. 2016). Increased KL expression may constitute a second positive feedback loop to increase FGF23 production in TIO tumours, suggesting that the autocrine stimulation of FGF23 and the manifestations of TIO may be KL-dependent, however this requires further study (Kinoshita et al. 2019). 


\section{Non-canonical FGF23 signalling}

KL-independent activation of the MAPK, calcineurin/ NFAT, and PLC pathways by FGF23 is essential for the actions of FGF23 other than regulation of renal phosphate excretion and is referred to as 'non-canonical' FGF23 signalling. The first evidence for KL-independent effects of FGF23 was the discovery that this hormone can cause LVH in Kl-null mice, which have extremely elevated circulating FGF23 levels (Faul et al. 2011, Grabner et al. 2015). Changes consistent with LVH in isolated rat cardiomyocytes can be prevented by treatment with inhibitors of PLCy and calcineurin/NFAT (Faul et al. 2011). It was later shown that this effect of FGF23 is mediated by FGFR4, and in turn, genetic ablation or pharmacological inhibition of FGFR4 reduced the development of LVH in isolated murine cardiomyocytes and rats with CKD, respectively (Fig. 2D) (Grabner et al. 2015). Myocardiocytespecific conditional ablation of FGFR4 in a mouse model also prevents FGF23-induced LVH (Han et al. 2020). Interestingly, LVH is not observed in the Hyp mouse model of X-linked hypophosphatemia (XLH) (Liu et al. 2018), which may be because FGF23 in Hyp and XLH is only mildly elevated and because hyperphosphatemia, a possible co-factor for the development of LVH in CKD, is missing in this disorder.

Skeletal muscle like cardiac muscle expresses FGFR1-4, $\mathrm{KL}$, and even FGF23; however, no effect of FGF23 on fibre diameter and ex-vivo excitation-contraction testing was shown (Avin et al. 2018).

KL-independent signalling was also described in the skeleton. FGF23 inhibits expression of tissue nonspecific alkaline phosphatases (TNAP) (Murali et al. 2016b) in femurs obtained from newborn WT and $\mathrm{Kl}$-null mice (Fig. 2E). Further work using specific FGFR inhibitors showed that TNAP suppression depends on FGFR3 and activation of ERK1/2 (Murali et al. 2016b). Suppression of TNAP is also thought to be a possible mechanism for the mineralisation defects seen in XLH and inhibiting FGF23 or FGF23-FGFR3 binding was able to partially restore TNAP expression and the mineralisation defect in Hyp mice (Murali et al. 2016a). Furthermore the osteoclast markers matrix metalloproteinase 13 (MMP13) and cathepsin K (CTSK) are elevated in Hyp mice and thought to be one mechanism why treatment with anti-FGF23 antibodies decreased bone resorption (Tokarz et al. 2018). Further work is needed to show which signalling pathway is involved and if this is a Klotho-independent effect.

FGF23 may also play a role as a negative regulator of erythropoiesis. This role was initially discovered by the observation of increased red blood counts in FGF23-null mice, which may be mediated by increased circulating erythropoietin (EPO) levels (Coe et al. 2014). Conversely, injection of FGF23 into WT mice decreased both EPO and functional erythroid cell counts (Coe et al. 2014). Elevated levels of FGF23 in patients with CKD who suffer from anaemia may contribute to failure of the kidneys to produce erythropoietin (EPO) (Babitt \& Lin 2012). Thus EPO closes a feedback loop whereby iron deficiency stimulates EPO and FGF23, which in turn inhibits EPO and erythropoiesis. KL and FGFR1, 3, and 4 are highly expressed in erythroid cells (Coe et al. 2014). Kl-null mice have increased EPO and erythrocyte counts, although hematopoiesis is also impaired in KL deficiency (Vadakke Madathil et al. 2014). However, whether regulation of EPO by FGF23 is KL-dependent and mediated by one of the FGFRs remains to be seen.

FGF23 finally impairs neutrophil activity in partially nephrectomised mice, a model for CKD, that was restored by neutralising FGF23 or by inhibition of FGFR2. Binding of FGF23 to FGFR2 was shown to be KL-independent in neutrophils, and leads to activation of protein kinase A and repression of the small GTPase Rap1, resulting in suppression of chemokine- and selectin-mediated integrin activation in neutrophils (Rossaint et al. 2016). Impaired neutrophil activity may be part of the impaired inflammatory responses commonly seen in CKD (RecioMayoral et al. 2011).

\section{Summary and future questions}

FGF23 is an endocrine FGF secreted by bone, which stimulates phosphate excretion in the kidneys like PTH, while different from PTH, FGF23 also inhibits synthesis of $1,25(\mathrm{OH})_{2} \mathrm{D}$. Both FGF23 actions lower Pi levels in the circulation and require canonical signalling through FGFR1c and the co-receptor KL. Conversely, FGF23 actions in the heart, parathyroids, bones, and erythrocytes are mediated mainly through FGFR3 and 4 in a KL-independent fashion, which is also referred to as noncanonical FGF23 signalling. FGF23 plays a significant role in the pathophysiology of many phosphate concentration disorders, including CKD, XLH, and TIO. We still need to understand better the functions of FGF23 fragments and the signal transduction pathways involved particularly for non-canonical FGF23 signalling to treat these disease processes better. It is also unclear why iron and phosphate homeostasis are co-regulated through FGF23 and EPO and what role inflammation plays for the regulation of FGF23 bioactivity. 


\section{Declaration of interest}

B B H declares to have no financial or other potential conflicts of interest that could be perceived as prejudicing the impartiality of the research reported. C B received research funds from Nutricia North America, Inc., Bethesda, $M D$, to study intestinal phosphate bioaccessibility and bioavailability in mice. He also serves on the Advisory Board for Bayer AG, Berlin, Germany.

\section{Funding}

$\mathrm{B} \mathrm{B} \mathrm{H}$ received funding through a training grant from the National Institutes of Health (NIH 5T35DK104689-05) and from the Yale School of Medicine START summer internship. C B received funding by The Yale O'Brien Center (NIH/NIDDK P30DK079310) and by Nutricia North America, Inc.

\section{References}

ADHR-Consortium 2000 Autosomal dominant hypophosphataemic rickets is associated with mutations in FGF23. Nature Genetics 26 345-348. (https://doi.org/10.1038/81664)

Agoro R, Park MY, Le Henaff C, Jankauskas S, Gaias A, Chen G, Mohammadi M \& Sitara D 2020 C-FGF23 peptide alleviates hypoferremia during acute inflammation. Haematologica 105 [epub]. (https://doi.org/10.3324/haematol.2019.237040)

Andrukhova O, Zeitz U, Goetz R, Mohammadi M, Lanske B \& Erben RG 2012 FGF23 acts directly on renal proximal tubules to induce phosphaturia through activation of the ERK1/2-SGK1 signaling pathway. Bone 51 621-628. (https://doi.org/10.1016/j. bone.2012.05.015)

Andrukhova O, Slavic S, Smorodchenko A, Zeitz U, Shalhoub V, Lanske B, Pohl EE \& Erben RG 2014 FGF23 regulates renal sodium handling and blood pressure. EMBO Molecular Medicine 6 744-759. (https://doi.org/10.1002/emmm.201303716)

Avin KG, Vallejo JA, Chen NX, Wang K, Touchberry CD, Brotto M, Dallas SL, Moe SM \& Wacker MJ 2018 Fibroblast growth factor 23 does not directly influence skeletal muscle cell proliferation and differentiation or ex vivo muscle contractility. American Journal of Physiology: Endocrinology and Metabolism 315 E594-E604. (https://doi. org/10.1152/ajpendo.00343.2017)

Babitt JL \& Lin HY 2012 Mechanisms of anemia in CKD. Journal of the American Society of Nephrology 23 1631-1634. (https://doi. org/10.1681/ASN.2011111078)

Beenken A \& Mohammadi M 2012 The structural biology of the FGF19 subfamily. In Endocrine FGFs and Klothos. Ed M Kuro-O. New York, NY, USA: Springer.

Ben-Dov IZ, Galitzer H, Lavi-Moshayoff V, Goetz R, Kuro-O M, Mohammadi M, Sirkis R, Naveh-Many T \& Silver J 2007 The parathyroid is a target organ for FGF23 in rats. Journal of Clinical Investigation 117 4003-4008. (https://doi.org/10.1172/JCI32409)

Burdine RD, Chen EB, Kwok SF \& Stern MJ 1997 egl-17 encodes an invertebrate fibroblast growth factor family member required specifically for sex myoblast migration in Caenorhabditis elegans. PNAS 94 2433-2437. (https://doi.org/10.1073/pnas.94.6.2433)

Carpenter TO, Bergwitz C \& Insogna KL 2020. Chapter 20 - Phosphorus homeostasis and related disorders. In Principles of Bone Biology, 4th ed. Eds JP Bilezikian, TJ Martin, TL Clemens \& CJ Rosen. Academic Press.

Chande S \& Bergwitz C 2018 Role of phosphate sensing in bone and mineral metabolism. Nature Reviews: Endocrinology 14 637-655. (https://doi.org/10.1038/s41574-018-0076-3)

Chang Q, Hoefs S, Van Der Kemp AW, Topala CN, Bindels RJ \& Hoenderop JG 2005 The beta-glucuronidase klotho hydrolyzes and activates the TRPV5 channel. Science 310 490-493. (https://doi. org/10.1126/science.1114245)
Château MT, Araiz C, Descamps S \& Galas S 2010 Klotho interferes with a novel FGF-signalling pathway and insulin/Igf-like signalling to improve longevity and stress resistance in Caenorhabditis elegans. Aging 2 567-581. (https://doi. org/10.18632/aging.100195)

Chen G, Liu Y, Goetz R, Fu L, Jayaraman S, Hu MC, Moe OW, Liang G, Li X \& Mohammadi M $2018 \alpha$-Klotho is a non-enzymatic molecular scaffold for FGF23 hormone signalling. Nature 553 461-466. (https:// doi.org/10.1038/nature25451)

Clinkenbeard EL \& White KE 2017 Heritable and acquired disorders of phosphate metabolism: etiologies involving FGF23 and current therapeutics. Bone 102 31-39. (https://doi.org/10.1016/j. bone.2017.01.034)

Coe LM, Madathil SV, Casu C, Lanske B, Rivella S \& Sitara D 2014 FGF23 is a negative regulator of prenatal and postnatal erythropoiesis. Journal of Biological Chemistry 289 9795-9810. (https://doi. org $/ 10.1074 /$ jbc.M113.527150)

Deliot N, Hernando N, Horst-Liu Z, Gisler SM, Capuano P, Wagner CA, Bacic D, O'Brien S, Biber J \& Murer H 2005 Parathyroid hormone treatment induces dissociation of type IIa $\mathrm{Na}+\mathrm{P}(\mathrm{i})$ cotransporter-Na+/H+ exchanger regulatory factor-1 complexes. American Journal of Physiology: Cell Physiology 289 C159-C167. (https://doi.org/10.1152/ajpcell.00456.2004)

DeVore DL, Horvitz HR \& Stern MJ 1995 An FGF receptor signaling pathway is required for the normal cell migrations of the sex myoblasts in C. elegans hermaphrodites. Cell 83 611-620. (https:// doi.org/10.1016/0092-8674(95)90101-9)

Duchesne L, Tissot B, Rudd TR, Dell A \& Fernig DG 2006 N-glycosylation of fibroblast growth factor receptor 1 regulates ligand and heparan sulfate co-receptor binding. Journal of Biological Chemistry $\mathbf{2 8 1}$ 27178-27189. (https://doi.org/10.1074/jbc.M601248200)

Edmonston D \& Wolf M 2020 FGF23 at the crossroads of phosphate, iron economy and erythropoiesis. Nature Reviews: Nephrology 16 7-19. (https://doi.org/10.1038/s41581-019-0189-5)

Eicher EM, Southard JL, Scriver CR \& Glorieux FH 1976 Hypophosphatemia: mouse model for human familial hypophosphatemic (vitamin D-resistant) rickets. PNAS $\mathbf{7 3}$ 4667-4671. (https://doi.org/10.1073/pnas.73.12.4667)

Eren M, Place AT, Thomas PM, Flevaris P, Miyata T \& Vaughan DE 2017 PAI-1 is a critical regulator of FGF23 homeostasis. Science Advances 3 e1603259. (https://doi.org/10.1126/sciadv.1603259)

Farrow EG, Davis SI, Summers LJ \& White KE 2009 Initial FGF23mediated signaling occurs in the distal convoluted tubule. Journal of the American Society of Nephrology 20 955-960. (https://doi. org/10.1681/ASN.2008070783)

Faul C 2012 Fibroblast growth factor 23 and the heart. Current Opinion in Nephrology and Hypertension 21 369-375. (https://doi.org/10.1097/ MNH.0b013e32835422c4)

Faul C, Amaral AP, Oskouei B, Hu MC, Sloan A, Isakova T, Gutierrez OM, Aguillon-Prada R, Lincoln J, Hare JM, et al. 2011 FGF23 induces left ventricular hypertrophy. Journal of Clinical Investigation 121 4393-4408. (https://doi.org/10.1172/JCI46122)

Gamba G, Saltzberg SN, Lombardi M, Miyanoshita A, Lytton J, Hediger MA, Brenner BM \& Hebert SC 1993 Primary structure and functional expression of a cDNA encoding the thiazide-sensitive, electroneutral sodium-chloride cotransporter. PNAS 90 2749-2753. (https://doi.org/10.1073/pnas.90.7.2749)

Gattineni J, Bates C, Twombley K, Dwarakanath V, Robinson ML, Goetz R, Mohammadi M \& Baum M 2009 FGF23 decreases renal $\mathrm{NaPi}-2 \mathrm{a}$ and NaPi-2c expression and induces hypophosphatemia in vivo predominantly via FGF receptor 1. American Journal of Physiology: Renal Physiology 297 F282-F291. (https://doi.org/10.1152/ ajprenal.90742.2008)

Goetz R, Nakada Y, Hu MC, Kurosu H, Wang L, Nakatani T, Shi M, Eliseenkova AV, Razzaque MS, Moe OW, et al. 2010 Isolated C-terminal tail of FGF23 alleviates hypophosphatemia by inhibiting 
FGF23-FGFR-klotho complex formation. PNAS 107 407-412. (https:// doi.org/10.1073/pnas.0902006107)

Goldfarb M, Schoorlemmer J, Williams A, Diwakar S, Wang Q, Huang X, Giza J, Tchetchik D, Kelley K, Vega A, et al. 2007 Fibroblast growth factor homologous factors control neuronal excitability through modulation of voltage-gated sodium channels. Neuron 55 449-463. (https://doi.org/10.1016/j.neuron.2007.07.006)

Grabner A, Amaral AP, Schramm K, Singh S, Sloan A, Yanucil C, Li J, Shehadeh LA, Hare JM, David V, et al. 2015 Activation of cardiac fibroblast growth factor receptor 4 causes left ventricular hypertrophy. Cell Metabolism 22 1020-1032. (https://doi. org/10.1016/j.cmet.2015.09.002)

Han X, Yang J, Li L, Huang J, King G \& Quarles LD 2016 Conditional deletion of FGFR1 in the proximal and distal tubule identifies distinct roles in phosphate and calcium transport. PLOS ONE 11 e0147845. (https://doi.org/10.1371/journal.pone.0147845)

Han X, Cai C, Xiao Z \& Quarles LD 2020 FGF23 induced left ventricular hypertrophy mediated by FGFR4 signaling in the myocardium is attenuated by soluble klotho in mice. Journal of Molecular and Cellular Cardiology 138 66-74. (https://doi.org/10.1016/j. yjmcc.2019.11.149)

Hesse M, Fröhlich LF, Zeitz U, Lanske B \& Erben RG 2007 Ablation of vitamin D signaling rescues bone, mineral, and glucose homeostasis in Fgf-23 deficient mice. Matrix Biology 26 75-84. (https://doi. org/10.1016/j.matbio.2006.10.003)

Hoenderop JG, De Pont JJ, Bindels RJ \& Willems PH 1999 Hormonestimulated $\mathrm{Ca} 2+$ reabsorption in rabbit kidney cortical collecting system is cAMP-independent and involves a phorbol ester-insensitive PKC isotype. Kidney International 55 225-233. (https://doi. org/10.1046/j.1523-1755.1999.00228.x)

Huang P \& Stern MJ 2004 FGF signaling functions in the hypodermis to regulate fluid balance in C. elegans. Development 131 2595-2604. (https://doi.org/10.1242/dev.01135)

Ide N, Olauson H, Sato T, Densmore MJ, Wang H, Hanai JI, Larsson TE \& Lanske B 2016 In vivo evidence for a limited role of proximal tubular klotho in renal phosphate handling. Kidney International 90 348-362. (https://doi.org/10.1016/j.kint.2016.04.009)

Imura A, Tsuji Y, Murata M, Maeda R, Kubota K, Iwano A, Obuse C, Togashi K, Tominaga M, Kita N, et al. 2007 alpha-Klotho as a regulator of calcium homeostasis. Science 316 1615-1618. (https:// doi.org/10.1126/science.1135901)

Itoh N, Nakayama Y \& Konishi M 2016 Roles of FGFs as paracrine or endocrine signals in liver development, health, and disease. Frontiers in Cell and Developmental Biology 4 30. (https://doi.org/10.3389/ fcell.2016.00030)

Kinoshita Y, Takashi Y, Ito N, Ikegawa S, Mano H, Ushiku T, Fukayama M, Nangaku M \& Fukumoto S 2019 Ectopic expression of klotho in fibroblast growth factor 23 (FGF23)-producing tumors that cause tumor-induced rickets/osteomalacia (TIO). Bone Reports 10 100192. (https://doi.org/10.1016/j.bonr.2018.100192)

Kovesdy CP \& Quarles LD 2016 FGF23 from bench to bedside. American Journal of Physiology: Renal Physiology 310 F1168-F1174. (https://doi. org/10.1152/ajprenal.00606.2015)

Krajisnik T, Bjorklund P, Marsell R, Ljunggren O, Akerstrom G, Jonsson KB, Westin G \& Larsson TE 2007 Fibroblast growth factor-23 regulates parathyroid hormone and 1alpha-hydroxylase expression in cultured bovine parathyroid cells. Journal of Endocrinology 195 125-131. (https://doi.org/10.1677/JOE-07-0267)

Kuro-O M, Matsumura Y, Aizawa H, Kawaguchi H, Suga T, Utsugi T, Ohyama Y, Kurabayashi M, Kaname T, Kume E, et al. 1997 Mutation of the mouse klotho gene leads to a syndrome resembling ageing. Nature 390 45-51. (https://doi.org/10.1038/36285)

Kurosu H, Ogawa Y, Miyoshi M, Yamamoto M, Nandi A, Rosenblatt KP, Baum MG, Schiavi S, Hu MC, Moe OW, et al. 2006 Regulation of fibroblast growth factor-23 signaling by klotho. Journal of Biological Chemistry 281 6120-6123. (https://doi.org/10.1074/jbc.C500457200)
Lee JC, Su SY, Changou CA, Yang RS, Tsai KS, Collins MT, Orwoll ES, Lin CY, Chen SH, Shih SR, et al. 2016 Characterization of FN1FGFR1 and novel FN1-FGF1 fusion genes in a large series of phosphaturic mesenchymal tumors. Modern Pathology 29 1335-1346. (https://doi.org/10.1038/modpathol.2016.137).

Lindberg I, Pang HW, Stains JP, Clark D, Yang AJ, Bonewald L \& Li KZ 2015 FGF23 is endogenously phosphorylated in bone cells. Journal of Bone and Mineral Research 30 449-454. (https://doi.org/10.1002/ jbmr.2354)

Liu ES, Martins JS, Zhang W \& Demay MB 2018 Molecular analysis of enthesopathy in a mouse model of hypophosphatemic rickets. Development 145 dev163519. (https://doi.org/10.1242/dev.163519)

Mace ML, Gravesen E, Nordholm A, Olgaard K \& Lewin E 2018 Fibroblast growth factor (FGF) 23 regulates the plasma levels of parathyroid hormone in vivo through the FGF receptor in normocalcemia, but not in hypocalcemia. Calcified Tissue International 102 85-92. (https://doi.org/10.1007/s00223-017-0333-9)

Michigami T, Kawai M, Yamazaki M \& Ozono K 2018 Phosphate as a signaling molecule and its sensing mechanism. Physiological Reviews 98 2317-2348. (https://doi.org/10.1152/physrev.00022.2017)

Murali SK, Andrukhova O, Clinkenbeard EL, White KE \& Erben RG $2016 a$ Excessive osteocytic FGF23 secretion contributes to pyrophosphate accumulation and mineralization defect in Hyp mice. PLoS Biology 14 e1002427. (https://doi.org/10.1371/journal. pbio.1002427)

Murali SK, Roschger P, Zeitz U, Klaushofer K, Andrukhova O \& Erben RG $2016 b$ FGF23 regulates bone mineralization in a 1,25(OH)2D3 and klotho-independent manner. Journal of Bone and Mineral Research 31 129-142. (https://doi.org/10.1002/jbmr.2606)

Olauson H, Lindberg K, Amin R, Jia T, Wernerson A, Andersson G \& Larsson TE 2012 Targeted deletion of klotho in kidney distal tubule disrupts mineral metabolism. Journal of the American Society of Nephrology 23 1641-1651. (https://doi.org/10.1681/ ASN.2012010048)22878961.

Olauson H, Lindberg K, Amin R, Sato T, Jia T, Goetz R, Mohammadi M, Andersson G, Lanske B \& Larsson TE 2013 Parathyroid-specific deletion of klotho unravels a novel calcineurin-dependent FGF23 signaling pathway that regulates PTH secretion. PLoS Genetics 9 e1003975. (https://doi.org/10.1371/journal.pgen.1003975)

Ornitz DM \& Itoh N 2015 The fibroblast growth factor signaling pathway. Wiley Interdisciplinary Reviews: Developmental Biology 4 215-266. (https://doi.org/10.1002/wdev.176)

Polanska UM, Duchesne L, Harries JC, Fernig DG \& Kinnunen TK 2009 $\mathrm{N}$-glycosylation regulates fibroblast growth factor receptor/EGL-15 activity in Caenorhabditis elegans in vivo. Journal of Biological Chemistry 284 33030-33039. (https://doi.org/10.1074/jbc. M109.058925)

Polanska UM, Edwards E, Fernig DG \& Kinnunen TK 2011 The cooperation of FGF receptor and klotho is involved in excretory canal development and regulation of metabolic homeostasis in Caenorhabditis elegans. Journal of Biological Chemistry 286 5657-5666. (https://doi.org/10.1074/jbc.M110.173039)

Recio-Mayoral A, Banerjee D, Streather C \& Kaski JC 2011 Endothelial dysfunction, inflammation and atherosclerosis in chronic kidney disease - a cross-sectional study of predialysis, dialysis and kidneytransplantation patients. Atherosclerosis 216 446-451. (https://doi. org/10.1016/j.atherosclerosis.2011.02.017)

Román-García P, Carrillo-López N, Naves-Díaz M, Rodríguez I, Ortiz A \& Cannata-Andía JB 2012 Dual-specificity phosphatases are implicated in severe hyperplasia and lack of response to FGF23 of uremic parathyroid glands from rats. Endocrinology 153 1627-1637. (https:// doi.org/10.1210/en.2011-1770)

Rose E, Lee D, Xiao E, Zhao W, Wee M, Cohen J \& Bergwitz C 2019 Endocrine regulation of MFS2 by branchless controls phosphate excretion and stone formation in Drosophila renal tubules. Scientific Reports 9 8798. (https://doi.org/10.1038/s41598-019-45269-x) 
Rossaint J, Oehmichen J, Van Aken H, Reuter S, Pavenstädt HJ, Meersch M, Unruh M \& Zarbock A 2016 FGF23 signaling impairs neutrophil recruitment and host defense during CKD. Journal of Clinical Investigation 126 962-974. (https://doi.org/10.1172/ JCI83470)

Roubin R, Naert K, Popovici C, Vatcher G, Coulier F, Thierry-Mieg J, Pontarotti P, Birnbaum D, Baillie D \& Thierry-Mieg D 1999 let-756, a C. elegans fgf essential for worm development. Oncogene $\mathbf{1 8}$ 6741-6747. (https://doi.org/10.1038/sj.onc.1203074)

Segawa H, Yamanaka S, Ohno Y, Onitsuka A, Shiozawa K, Aranami F, Furutani J, Tomoe Y, Ito M, Kuwahata M, et al. 2007 Correlation between hyperphosphatemia and type II Na-Pi cotransporter activity in klotho mice. American Journal of Physiology: Renal Physiology 292 F769-F779. (https://doi.org/10.1152/ajprenal.00248.2006)

Sen A, Yokokura T, Kankel MW, Dimlich DN, Manent J, Sanyal S \& Artavanis-Tsakonas S 2011 Modeling spinal muscular atrophy in Drosophila links Smn to FGF signaling. Journal of Cell Biology 192 481-495. (https://doi.org/10.1083/jcb.201004016)

Shimada T, Mizutani S, Muto T, Yoneya T, Hino R, Takeda S, Takeuchi Y, Fujita T, Fukumoto S \& Yamashita T 2001 Cloning and characterization of FGF23 as a causative factor of tumor-induced osteomalacia. PNAS 98 6500-6505. (https://doi.org/10.1073/ pnas.101545198)

Shimada T, Kakitani M, Yamazaki Y, Hasegawa H, Takeuchi Y, Fujita T, Fukumoto S, Tomizuka K \& Yamashita T 2004 Targeted ablation of FGF23 demonstrates an essential physiological role of FGF23 in phosphate and vitamin D metabolism. Journal of Clinical Investigation 113 561-568. (https://doi.org/10.1172/JCI19081)

Szewczyk NJ \& Jacobson LA 2003 Activated EGL-15 FGF receptor promotes protein degradation in muscles of Caenorhabditis elegans. EMBO Journal 22 5058-5067. (https://doi.org/10.1093/emboj/cdg472)

Tagliabracci VS, Engel JL, Wiley SE, Xiao J, Gonzalez DJ, Nidumanda Appaiah H, Koller A, Nizet V, White KE \& Dixon JE 2014 Dynamic regulation of FGF23 by Fam20C phosphorylation, GalNAc-T3 glycosylation, and furin proteolysis. PNAS 111 5520-5525. (https:// doi.org/10.1073/pnas.1402218111)

Takashi Y \& Fukumoto S 2020 Phosphate-sensing and regulatory mechanism of FGF23 production. Journal of Endocrinological
Investigation 43 877-883. (https://doi.org/10.1007/s40618020-01205-9)

Takeshita A, Kawakami K, Furushima K, Miyajima M \& Sakaguchi K 2018 Central role of the proximal tubular $\alpha$ Klotho/FGF receptor complex in FGF23-regulated phosphate and vitamin D metabolism. Scientific Reports 8 6917. (https://doi.org/10.1038/s41598-01825087-3)

Tohyama O, Imura A, Iwano A, Freund JN, Henrissat B, Fujimori T \& Nabeshima Y-I 2004 Klotho is a novel $\beta$-glucuronidase capable of hydrolyzing steroid $\beta$-glucuronides. Journal of Biological Chemistry 279 9777-9784. (https://doi.org/10.1074/jbc.M312392200)

Tokarz D, Martins JS, Petit ET, Lin CP, Demay MB \& Liu ES 2018 Hormonal regulation of osteocyte perilacunar and canalicular remodeling in the Hyp mouse model of X-linked hypophosphatemia. Journal of Bone and Mineral Research 33 499-509. (https://doi.org/10.1002/jbmr.3327)

Urakawa I, Yamazaki Y, Shimada T, Iijima K, Hasegawa H, Okawa K, Fujita T, Fukumoto S \& Yamashita T 2006 Klotho converts canonical FGF receptor into a specific receptor for FGF23. Nature $\mathbf{4 4 4}$ 770-774. (https://doi.org/10.1038/nature05315)

Vadakke Madathil S, Coe LM, Casu C \& Sitara D 2014 Klotho deficiency disrupts hematopoietic stem cell development and erythropoiesis. American Journal of Pathology 184 827-841. (https://doi. org/10.1016/j.ajpath.2013.11.016)

Wolf M \& White KE 2014 Coupling fibroblast growth factor 23 production and cleavage: iron deficiency, rickets, and kidney disease. Current Opinion in Nephrology and Hypertension 23 411-419. (https:// doi.org/10.1097/01.mnh.0000447020.74593.6f)

Yamashita T, Yoshioka M \& Itoh N 2000 Identification of a novel fibroblast growth factor, FGF-23, preferentially expressed in the ventrolateral thalamic nucleus of the brain. Biochemical and Biophysical Research Communications 277 494-498. (https://doi. org/10.1006/bbrc.2000.3696)

Yoshida T, Fujimori T \& Nabeshima Y 2002 Mediation of unusually high concentrations of 1,25-dihydroxyvitamin D in homozygous klotho mutant mice by increased expression of renal 1alpha-hydroxylase gene. Endocrinology 143 683-689. (https://doi.org/10.1210/ endo.143.2.8657)

Received in final form 7 October 2020

Accepted 20 November 2020

Accepted Manuscript published online 9 December 2020 (c) 2021 Society for Endocrinology Published by Bioscientifica Ltd. Printed in Great Britain 